\title{
IPSS Risk Score 0.5 to 1.0
}

National Cancer Institute

\section{Source}

National Cancer Institute. IPSS Risk Score 0.5 to 1.0. NCI Thesaurus. Code C139298.

An International Prognostic Scoring System for Myelodysplastic Syndrome risk score of 0.5 to 1.0 , corresponding to intermediate- 1 risk. 